\title{
Effects of Local Anesthetic on the Time Between Analgesic Boluses and the Duration of Labor in Patient-Controlled Epidural Analgesia: Prospective Study of Two Ultra- Low Dose Regimens of Ropivacaine and Sufentanil
}

\author{
Efeitos de Anestésico Local no Tempo Entre Bólus e na Duração do Trabalho \\ de Parto em Patient-Controlled Epidural Analgesia: Estudo Prospectivo de \\ Dois Regimes de Doses Ultra-Baixas com Ropivacaina e Sufentanil
}

José Manuel COSTA-MARTINS ${ }^{1}$, Cláudia Camila DIAS ${ }^{2}$, Marco PEREIRA $^{3}$, Jorge TAVARES ${ }^{4}$

Acta Med Port 2015 Jan-Feb;28(1):70-76

\section{ABSTRACT}

Background: Patient-controlled epidural analgesia with low concentrations of anesthetics is effective in reducing labor pain. The aim of this study was to assess and compare two ultra-low dose regimens of ropivacaine and sufentanil $(0.1 \%$ ropivacaine plus $0.5 \mu \mathrm{g}$.ml- 1 sufentanil vs. $0.06 \%$ ropivacaine plus $0.5 \mu \mathrm{g} \cdot \mathrm{ml}^{-1}$ sufentanil) on the intervals between boluses and the duration of labor.

Material and Methods: In this non-randomized prospective study, conducted between January and July 2010, two groups of parturients received patient-controlled epidural analgesia: Group I $\left(n=58 ; 1 \mathrm{mg} \mathrm{ml}^{-1}\right.$ ropivacaine $+0.5 \mu \mathrm{g} \cdot \mathrm{ml}^{-1}$ sufentanil) and Group II ( $\mathrm{n}=57 ; 0.6 \mathrm{mg} \cdot \mathrm{ml}^{-1}$ ropivacaine $+0.5 \mu \mathrm{g} \cdot \mathrm{ml}^{-1}$ sufentanil). Rescue doses of ropivacaine at the concentration of the assigned group without sufentanil were administered as necessary. Pain, local anesthetic requirements, neuraxial blockade characteristics, labor and neonatal outcomes, and maternal satisfaction were recorded.

Results: The ropivacaine dose was greater in Group I (9.5 [7.7-12.7] mg.h ${ }^{-1}$ vs. 6.1 [5.1-9.8 mg.h-1 $\left.], p<0.001\right)$. A time increase between each bolus was observed in Group I (beta $=32.61 \mathrm{~min}, 95 \% \mathrm{Cl}$ [25.39; 39.82], $p<0.001$ ), whereas a time decrease was observed in Group II (beta $=-1.40 \mathrm{~min}, 95 \% \mathrm{Cl}[-2.44 ;-0.36], p=0.009)$. The duration of the second stage of labor in Group I was significantly longer than that in Group II (78 min vs. 65 min, $p<0.001)$.

Conclusions: Parturients receiving $0.06 \%$ ropivacaine exhibited less evidence of cumulative effects and exhibited faster second stage progression than those who received $0.1 \%$ ropivacaine.

Keywords: Analgesia, Obstetrical; Analgesia, Patient-Controlled; Labor Pain; Ropivacaine; Sufentanil.

\section{RESUMO}

Introdução: A patient-controlled epidural analgesia com baixas concentrações de anestésicos é eficaz na redução da dor de parto. O objectivo deste estudo foi comparar dois regimes de doses ultrabaixas de ropivacaína e sufentanil $(0,1 \%$ ropivacaína associada a $0,5 \mu \mathrm{g} \cdot \mathrm{ml}^{-1}$ sufentanil vs. $0,06 \%$ ropivacaína associada a $0,5 \mu \mathrm{g} \cdot \mathrm{ml}^{-1}$ sufentanil) nos intervalos entre bólus e na duração do trabalho de parto.

Material e Métodos: Neste estudo prospectivo não-randomizado, realizado entre Janeiro e Julho de 2010, dois grupos de parturientes receberam patient-controlled epidural analgesia: o Grupo I ( $n=58 ; 1$ mg. $\mathrm{ml}^{-1}$ ropivacaína $+0,5 \mu \mathrm{g} \cdot \mathrm{ml}^{-1}$ sufentanil) e o Grupo II ( $\mathrm{n}=57$; $0,6 \mathrm{mg} \mathrm{ml}^{-1}$ ropivacaína $+0,5 \mu \mathrm{g} \cdot \mathrm{ml}^{-1}$ sufentanil). Quando necessário administraram-se doses de resgate de ropivacaína na concentração definida para cada grupo e sem sufentanil. Registaram-se a dor, os consumos de analgésicos, as características do bloqueio neuroaxial, do trabalho de parto, do recém-nascido, e a satisfação materna.

Resultados: A dose de ropivacaína foi maior no Grupo I (9,5 [7,7-12,7] mg.h-1 vs. 6,1 [5,1-9,8 mg.h-1], $p<0,001)$. No Grupo I observouse um aumento do intervalo de tempo entre bólus (beta $=32,61 \mathrm{~min}, 95 \% \mathrm{Cl}[25,39 ; 39,82], p<0,001$ ), enquanto no Grupo II se observou uma diminuição dos intervalos (beta $=-1,40 \mathrm{~min}, 95 \% \mathrm{Cl}[-2,44 ;-0,36], p=0,009$ ). A duração do segundo estadio do trabalho de parto foi significativamente maior no Grupo I do que no Grupo II (78 min vs. $65 \mathrm{~min}, p<0,001)$.

Conclusões: As parturientes que receberam ropivacaína a $0,06 \%$ exibiram uma menor evidência de efeitos cumulativos e um segundo estadio do trabalho de parto mais rápido do que as que receberam ropivacaína a $0,1 \%$.

Palavras-chave: Analgesia Controlada pelo Doente; Analgesia Obstétrica; Dor do Parto; Ropivacaína; Sufentanil.

\section{INTRODUCTION}

Patient-controlled epidural analgesia (PCEA) has promoted significant progress in the optimization of therapeutics for labor pain and has resulted in greater satisfaction among women, who enjoy a certain level of autonomy. ${ }^{1-4}$ Additionally, PCEA leads to decreased anesthetic administration, smaller rescue doses, and a

1. Departamento de Anestesiologia. Maternidade Alfredo da Costa. Lisboa. Portugal.

2. Departamento de Ciências da Informação e da Decisão em Saúde. Faculdade de Medicina. Universidade do Porto. Porto. Portugal.

3. Faculdade de Psicologia e de Ciências da Educação. Universidade de Coimbra. Coimbra. Portugal.

4. Departamento de Anestesiologia. Hospital de São João. Faculdade de Medicina. Universidade do Porto. Porto. Portugal.

Recebido: 29 de Julho de 2014 - Aceite: 15 de Dezembro de 2014 | Copyright $\odot$ Ordem dos Médicos 2015 
lower incidence of motor blockade.,25-8 PCEA has been used during labor with or without continuous background infusion, ${ }^{1,4,7-10}$ with boluses of different volumes, and with variable lockout intervals. ${ }^{1,2}$ Protocols with low concentrations of ropivacaine allow for effective analgesia and significantly higher parturient mobility, ${ }^{11,12}$ even when the technique is initiated during the early stages of labor. ${ }^{13}$ The efficacy of PCEA during labor is related to the local anesthetic dose used, ${ }^{11}$ however, a higher administration of local anesthetics has been related to a prolonged second stage of labor. ${ }^{9}$

Despite the multiple approaches and significant progress that has been achieved in labor PCEA research, to the best of our knowledge, no studies have tested the possible time-dependent cumulative effects resulting from the administration of analgesia throughout labor, even using low-dose regimens. Therefore, we aimed to test the hypothesis that as analgesia progresses, higher doses of local anesthetics increase the intervals between boluses (cumulative effect). More specifically, we aimed to assess and compare the effects of local anesthetic doses on the intervals between analgesic boluses (primary outcome) and the duration of labor (secondary outcome) using two ultralow dose PCEA protocols with ropivacaine and sufentanil $\left(0.1 \%\right.$ ropivacaine plus $0.5 \mu \mathrm{g} \cdot \mathrm{ml}^{-1}$ sufentanil vs. $0.06 \%$ ropivacaine plus $0.5 \mu \mathrm{g} \cdot \mathrm{ml}^{-1}$ sufentanil).

\section{MATERIAL AND METHODS}

This non-randomized prospective study was conducted in compliance with the Helsinki Declaration and was approved by the Ethics Commission of the Maternity Hospital Alfredo da Costa (Lisbon, Portugal) and by the National Board of Data Protection. The participants' confidentialities were ensured, and they all provided written informed consent.

The sample collection took place between January and July 2010. Upon request for labor analgesia women were consecutively recruited by the team of anesthesiologists at the time they requested analgesia. All women who matched the inclusion criteria were allocated to one of two teams of anesthesiologists depending on their availability at the maternity hospital (by convenience). Each team applied one of the two PCEA protocols. The attending anesthesiologists were not blinded to the group assignments. However, the participants and obstetric staff (obstetricians and midwives) that monitored and recorded labor progression were blinded to the group assignments.

The following inclusion criteria were applied: healthy pregnancy and singleton, normosomic fetus in a vertex presentation; nulliparous and parous (until the third pregnancy); age $\geq 18$ and $\leq 40$ years; active labor (regular contractions and cervical dilation $\geq 3 \mathrm{~cm}$ ); absence of contraindications to epidural blockade; absence of previous analgesia with opioids; American Society of Anesthesiologists (ASA) physical status I or II; absence of cephalopelvic disproportion; no history of caesarean for dystocia; absence of psychopathological disorders and substance abuse. During labor, the parturients that progressed to caesarean section in the first stage were excluded from the study.

The same PCEA equipment was used in both groups (CADD ${ }^{\circledR}$-Solis Smart pump, Smiths Medical MD, Inc., St. Paul, MN, USA), and the participants received specific instructions to press the button when they began to feel discomfort. Group I received ropivacaine $\left(1 \mathrm{mg} \cdot \mathrm{ml}^{-1}\right)$ plus sufentanil $\left(0.5 \mu \mathrm{g} \cdot \mathrm{ml}^{-1}\right)$ as follows: a $10-12 \mathrm{ml}$ loading dose, 5 $\mathrm{ml} . \mathrm{h}^{-1}$ background infusion, $5 \mathrm{ml}$ patient-controlled bolus, 15 min lockout, and $20 \mathrm{ml} . \mathrm{h}^{-1}$ limit. Group II received ropivacaine $\left(0.6 \mathrm{mg} \mathrm{ml}^{-1}\right)$ plus sufentanil $\left(0.5 \mu \mathrm{g} \cdot \mathrm{ml}^{-1}\right)$ as follows: a $10-12$ $\mathrm{ml}$ loading dose, $3 \mathrm{ml} . \mathrm{h}^{-1}$ background infusion, $5 \mathrm{ml}$ patientcontrolled bolus, $15 \mathrm{~min}$ lockout, and $20 \mathrm{ml} . \mathrm{h}^{-1}$ limit. Selfdelivered boluses were infused at a standard delivery rate of $175 \mathrm{ml}^{-1} \mathrm{~h}^{-1}$ (one bolus per $103 \mathrm{sec}$ ). These regimens were maintained in both groups during both the early and late stages of labor. A 3-5 cm length of a multi-eyed epidural catheter (Portex ${ }^{\odot}$, Rossendale, UK) was introduced into the epidural space, and then, an aspiration test was performed to check for blood or cerebrospinal fluid. The first $5 \mathrm{ml}$ of the loading dose served to identify the intrathecal location of the catheter. Upon parturient request, a rescue dose of 8-10 ml of ropivacaine at the concentration of the assigned group was administered without opioids. The parturients were instructed on the use of the PCEA pump before the epidural catheter was inserted. The instructions included specific directions to each woman to press the button whenever she began to feel discomfort, and to wait a few minutes in order to feel its analgesic effect.

According to the local institutional protocol, after epidural analgesia was established, all parturients received an oxytocin infusion (10U.1000 $\mathrm{ml}^{-1}$ ) with an initial dose of $4 \mathrm{mU} \cdot \mathrm{min}^{-1}$ and increments of $4-5 \mathrm{mU} \cdot \mathrm{min}^{-1}$ every $2 \mathrm{~h}$, until a maximum dose of $15 \mathrm{mU} \cdot \mathrm{min}^{-1}$, adjusted to ensure a medium progression of $1 \mathrm{~cm} \cdot \mathrm{h}^{-1}$ in cervical dilatation.

Arterial pressure, heart rate, sensory blockade (loss of sensation to cold) and motor blockade (modified Bromage scale: 0 - full flexion of feet and knees; 1 - just able to move knees; 2 - able to move feet only; 3 - unable to move feet or knees) and the presence of pruritus and nausea were assessed in all of the parturients at 20 and 60 min after the analgesic induction and every $2 \mathrm{~h}$ thereafter. Maternal hypotension was defined as a $>20 \%$ decrease below baseline or a systolic value $<100 \mathrm{~mm} \mathrm{Hg}$ and was treated according to the institutional protocol, as follows: left lateral uterine displacement, the application of an oxygen mask, increased fluid therapy, and if necessary, treatment with an ephedrine bolus (5 mg). During labor, tocodynamometry was performed, and the fetal heart rate was continuously monitored.

Each parturient's demographics, obstetric history, physical variables, and labor characteristics as well as the newborn's birth weight and Apgar scores at 1 and 5 min were recorded. At the beginning of analgesia, the degree of cervical dilation and the presence or absence of oxytocin infusion were recorded. During the first hour after delivery, the level of maternal satisfaction with labor of the 
parturient was assessed by a midwife (also blinded to group assignment) according to the following categorizations: excellent, good, fair, or poor.

Pain intensity was evaluated with a visual analog scale (VAS) $(0 \mathrm{~mm}$ [no pain] to $100 \mathrm{~mm}$ [worst imaginable pain]) by averaging the values of two consecutive uterine contractions before the beginning of analgesia (baseline VAS) and before the administration of each supplementary bolus request (rescue VAS). To determine the local anesthetic requirements and analgesic characteristics, the following values were recorded: the duration of analgesia (the time from the beginning of analgesia until delivery), the total volume of analgesic solution, the total and average hourly doses of ropivacaine and sufentanil, the number of boluses, the ratio of PCEA demands/PCEA delivered, the number of rescues during the first and second stages, the percentage of parturients who requested rescue doses during the first and second stages, and the time intervals between analgesic administrations.

For the computation of the primary outcome (the intervals between boluses), both self-delivered and rescue doses were considered because they reflected the concrete analgesic needs of each woman. These data were obtained from the records of the PCEA infusion pump, which were downloaded to a computer as individual reports using the $\mathrm{CADD}^{\odot}$-Solis Medication Safety Software-Administrator, part number 97-0442-25C, version 2.0.24, database version 7.7 (Smiths Medical). The times of the rescue doses were recorded by the anesthesiologists. For the secondary outcome (duration of labor), the first stage of labor was defined as the time from analgesia establishment until full dilation, and the second stage was defined as the time between full cervical dilatation and the completion of vaginal delivery or the decision to proceed with cesarean delivery. Although the monitoring of the progression of cervical dilatation is a routine procedure that is performed by all obstetric staff at our maternity hospital, to increase the accuracy of the assessment of this outcome, the importance of carefully recording the time of full dilatation was communicated to the obstetric teams.

\section{Statistical analysis}

For the statistical analysis, the categorical variables were expressed as absolute and relative frequencies, and the continuous variables were expressed as means and standard deviations (SD) or medians and percentiles (P05 and P95), depending on their symmetries and distributions. Independent-sample t-tests were applied if the variables were assumed to be normally distributed. Additionally, hypotheses about the distribution of continuous variables with non-normal distribution were tested with the Mann-Whitney or Kruskal-Wallis non-parametrical tests, depending on the nature of the tested hypotheses. Categorical variables were compared with the chi-square test or Fisher's exact test, as appropriate. To evaluate the time intervals between doses for both groups, multivariate models of generalized estimation equations (GEEs) were used with the assumption of identity as a connecting function (i.e., a linear evolution in time). GEEs enable the analysis of repeated or longitudinal measurements, considering that measurements from the same individual over time are correlated. An advantage of this type of model is that it produces consistent estimations of the parameters that are associated with the model's covariates, even if the assumed structure of the correlation is incorrect ${ }^{14,15}$. Defining TT as the time between doses and $\mathrm{n}$ as the number of times that the drugs were administered produces the following equation:

$\mathrm{TT}(\mathrm{n}, \mathrm{n}-1)=$ constant + beta * $(\mathrm{n}-1)$

Thus, to calculate the time between the second and third doses, the equation would be TT $(3,2)=$ constant * beta * 2 .

Post-hoc power calculations at a confidence level of $95 \%$ and power of $\geq 0.80$ indicated that the achieved sample size allowed for the detection of medium effects ${ }^{16}$. A $p$ value of $\leq 0.05$ was considered to be statistically significant. The statistical software IBM SPSS version 20.0 (Statistical Package for the Social Sciences) was used for the data analysis.

\section{RESULTS}

Group I ( $0.1 \%$ ropivacaine) included 67 parturients, and nine were excluded (three due to incomplete data, three due to progression to caesarean section in the first stage of labor, and three due to deviation from the protocol). Group II $(0.06 \%$ ropivacaine) included 64 parturients, and seven were excluded (four due to incomplete data, two due to progression to caesarean section in the first stage of labor, and one due to deviation from the protocol). The final sample consisted of 115 parturients, including 58 in Group I and 57 in Group II. The demographic and obstetric characteristics of the two groups were not significantly different (Table 1).

The time intervals between boluses were longer in Group I $(p<0.001)$. Additionally, the number of boluses differed, with a significantly higher number in Group II ( $p<$ $0.001)$. The total and average hourly doses of ropivacaine were higher in Group I than in Group II $(p<0.001)$. There were no significant differences between the groups in the duration of analgesia, total or average hourly doses of sufentanil, sensory levels, the total volumes of analgesic solution, the ratios of PCEA demands/PCEA delivered, the proportions of women who requested rescues during the first and second stage of labor, or VAS pain scores (Table 2). The side effects were also similar in both groups (Table 3 ). No cases of maternal bradycardia and hypotension were recorded in both groups.

Neonatal outcomes (newborn weight and Apgar scores) and maternal satisfaction with labor were comparable between the groups (Table 1).

In Group I, the time interval between each bolus increased by $32.6 \mathrm{~min}(95 \% \mathrm{Cl}[25.29 ; 39.82])$, whereas it decreased by 1.40 min $(95 \% \mathrm{Cl}[-2.44 ;-0.36])$ in Group II. These results were statistically significant (Table 4).

There were no differences in the duration of the first stage of labor. The duration of the second stage of labor 
Table 1 - Parturients demographics and labor characteristics

\begin{tabular}{|c|c|c|c|}
\hline & $\begin{array}{l}\text { Group I } \\
(n=58)\end{array}$ & $\begin{array}{l}\text { Group II } \\
(n=57)\end{array}$ & $p$ \\
\hline Age & $26.05 \pm 4.26$ & $27.71 \pm 5.37$ & 0.068 \\
\hline $\mathrm{BMI}^{*}$ & $23.29 \pm 3.02$ & $23.17 \pm 3.43$ & 0.844 \\
\hline Nulliparous & $28(48.3)$ & $29(50.9)$ & 0.853 \\
\hline Dysmenorrhea & $8(13.8)$ & $6(10.5)$ & 0.777 \\
\hline Low back menstrual pain & $17(29.3)$ & $18(29.8)$ & 1.000 \\
\hline Oxytocin induction $^{\dagger}$ & $41(70.7)$ & $38(66.7)$ & 0.691 \\
\hline Cervical dilatation ${ }^{\ddagger}$ & $4(3-4)$ & $4(3-4)$ & 0.577 \\
\hline \multicolumn{4}{|l|}{ Mode of delivery } \\
\hline Vaginal & $41(70.7)$ & $42(73.7)$ & \\
\hline Instrumental & $9(15.5)$ & $7(12.3)$ & 0.881 \\
\hline Caesarean & $8(13.8)$ & $8(14.0)$ & \\
\hline Newborn weight $(\mathrm{kg})$ & $3.32 \pm 0.34$ & $3.29 \pm 0.33$ & 0.671 \\
\hline Apgar $<7$ at $1 \mathrm{~min}$ & $8(13.8)$ & $4(7.0)$ & 0.361 \\
\hline Apgar $<7$ at $5 \mathrm{~min}$ & $0(0)$ & $0(0)$ & 1.000 \\
\hline \multicolumn{4}{|l|}{ Duration of labor (min) } \\
\hline First stage ${ }^{\S}$ & $311 \pm 72$ & $337 \pm 84$ & 0.093 \\
\hline Second stage $\|^{\|}$ & $78 \pm 15$ & $65 \pm 19$ & $<0.001$ \\
\hline \multicolumn{4}{|l|}{ Maternal satisfaction } \\
\hline Excellent & $37(63.8)$ & $39(68.4)$ & \\
\hline Good & $20(34.5)$ & $17(29.8)$ & 0.866 \\
\hline Fair & $1(1.7)$ & $1(1.8)$ & \\
\hline
\end{tabular}

Unless indicated, data are presented as number (\%), Mean \pm SD or Median (Percentil 05-Percentil 95). Group I: 0.1\% ropivacaine; Group II: $0.06 \%$ ropivacaine.

"Pre-pregnancy body mass index $\left(\mathrm{kg} . \mathrm{m}^{-2}\right) ;{ }^{\dagger}$ Percentage of patients receiving oxytocin before epidural administration; ${ }^{\ddagger}$ Cervical dilatation at time of epidural catheter insertion. ${ }^{\S}$ Time from study drug administration until total cervical dilation; "Time from full cervical dilation to vaginal delivery or decision to proceed to cesarean delivery.

Table 2 - Analgesic requirements and analgesia characteristics

\begin{tabular}{|c|c|c|c|c|c|}
\hline & \multicolumn{2}{|c|}{$\begin{array}{l}\text { Group I } \\
(n=58)\end{array}$} & \multicolumn{2}{|c|}{$\begin{array}{l}\text { Group II } \\
(n=57)\end{array}$} & $p$ \\
\hline Baseline VAS pain score* & \multicolumn{2}{|c|}{$89(73-100)$} & \multicolumn{2}{|c|}{$88(73-100)$} & 0.886 \\
\hline VAS pain score at supplementary boluses & \multicolumn{2}{|c|}{$80(48-99)$} & \multicolumn{2}{|c|}{$75(44-100)$} & 0.481 \\
\hline Sensory level ${ }^{\dagger}$ & \multicolumn{2}{|c|}{ T7 (T7-T8) } & \multicolumn{2}{|c|}{ T7 (T7-T8) } & 0.246 \\
\hline Duration of analgesia (min) & \multicolumn{2}{|c|}{$367(224-473)$} & \multicolumn{2}{|c|}{$315(182-563)$} & 0.066 \\
\hline Intervals between boluses (min) & \multicolumn{2}{|c|}{$47.5(23.0-109.7)$} & \multicolumn{2}{|c|}{$34.0(20.9-96.2)$} & $<0.001$ \\
\hline Total volume of analgesic solution (ml) & \multicolumn{2}{|c|}{$56.9(40.5-70.8)$} & \multicolumn{2}{|c|}{$55.6(37.5-93.7)$} & 0.933 \\
\hline Total dose of ropivacaine (mg) & \multicolumn{2}{|c|}{$57.0(40.6-70.8)$} & \multicolumn{2}{|c|}{$33.4(22.2-56.2)$} & $<0.001$ \\
\hline Average dose of ropivacaine $\left(\mathrm{mg} \cdot \mathrm{h}^{-1}\right)$ & \multicolumn{2}{|c|}{$9.5(7.7-12.7)$} & \multicolumn{2}{|c|}{$6.1(5.1-9.8)$} & $<0.001$ \\
\hline Total dose of sufentanil $(\mu \mathrm{g})$ & \multicolumn{2}{|c|}{$27.7(20.3-34.9)$} & \multicolumn{2}{|c|}{$27.2(18.4-45.1)$} & 0.687 \\
\hline Average dose of sufentanil $\left(\mu \mathrm{g} \cdot \mathrm{h}^{-1}\right)$ & \multicolumn{2}{|c|}{$4.7(3.8-6.1)$} & \multicolumn{2}{|c|}{$4.9(3.9-7.8)$} & 0.061 \\
\hline Number of boluses & \multicolumn{2}{|c|}{$3(2-4)$} & \multicolumn{2}{|c|}{$5(3-11)$} & $<0.001$ \\
\hline Ratio PCEA demands/PCEA delivered & \multicolumn{2}{|c|}{$1.78(1.25-3.01)$} & \multicolumn{2}{|c|}{$1.80(1.29-3.13)$} & 0.946 \\
\hline Women that requested rescues in 1 st stage & 5 & $(8.6)$ & 2 & $(3.5)$ & 0.438 \\
\hline $0-1$ rescues & 58 & $(100)$ & 55 & $(96.5)$ & 0243 \\
\hline$\geq 2$ rescues & 0 & (0) & 2 & $(3.5)$ & 0.243 \\
\hline Women that requested rescues in 2 nd stage & 14 & $(24.1)$ & 8 & $(14.0)$ & 0.236 \\
\hline $0-1$ rescues & 58 & $(100)$ & 57 & $(100)$ & \\
\hline$\geq 2$ rescues & 0 & $(0)$ & 0 & $(0)$ & - \\
\hline
\end{tabular}

Unless indicated, data are presented as median (Percentil 05-Percentil 95) or number (\%). Group I: 0.1\% ropivacaine; Group II: $0.06 \%$ ropivacaine.

"Pain score accessed by visual analogic scale $(\mathrm{mm})$; ${ }^{\dagger}$ Sensorial level to temperature 20, 60 min after study drug administration and 120 min assessment intervals.

was longer in Group I (78 \pm 15 ; range: 45-107) than in Group II (65 \pm 19 ; range: $38-104)$, and the difference was statistically significant $(p=0.001)$.

\section{DISCUSSION}

In this comparative study between the two PCEA protocols, the influences of the ropivacaine dose on the 
intervals between boluses and the duration of labor were assessed. Multiple types of PCEA have been adopted for use during labor, $6,9,17$ but no attention has been given to the possibility that local anesthetic doses, even using ultralow dose regimens, cause cumulative effects as analgesia progresses. Such effects may limit the evidence of individual differences in pain expression and analgesia and may have repercussions on the progress of labor.

The main finding of this study was that in Group I ( $0.1 \%$ ropivacaine), the time interval between each bolus increased, whereas in Group II $(0.06 \%$ ropivacaine $)$, it decreased. These results, which were obtained as the duration of analgesia and frequency of nociceptive stimulation increased, ${ }^{18}$ indicate opposite patterns in the two groups. Indeed, there was better dose-demand matching between the administered doses and labor progression in Group II, while the frequency of dose administration did not correspond with the increased frequency of uterine contractility in Group I (relative to labor progression). Considering that the advances in PCEA tend to allow for more flexible analgesic strategies that are tailored to the individual needs of the parturient and are effective throughout the different phases of labor, ${ }^{19}$ the pattern observed for Group II seems to indicate a better correspondence between analgesia and nociception in association with the lower cumulative dose of ropivacaine.

In this study, the duration of the second stage of labor was shorter in the group who was administered $0.06 \%$ ropivacaine. Due to the similarities of the settings and (most importantly) equal hourly volume limits, sufentanil concentrations, and opioid administrations in both groups, this finding seemed to depend largely upon variations in the ropivacaine dose. In addition, this result also reveals the impact of local anesthetic dose on labor duration, even using low-dose protocols, which was previously demonstrated by
Lim et al. ${ }^{9}$ Indeed, as has been suggested in a recent metaanalysis, ${ }^{20}$ a prolonged second stage of labor may be an effect of the concentration of local anesthetic, which was supported by our findings.

The relevance of these findings is reinforced by the absence of differences between the two groups in terms of sensory levels, factors related to pain (cervical dilation at the beginning of analgesia, previous oxytocin infusion, and the baseline pre-analgesia pain score), and major and minor predictors of pain (age, parity, history of dysmenorrhea, low back menstrual pain, and BMI). ${ }^{21,22}$

It is noteworthy that similarly to previous studies using low-concentration solutions of local anesthetics, ${ }^{23}$ this study showed low incidences of $\geq 2$ rescues for both groups (both in the first and second stage of labor). This is an important finding because it may indicate that despite the lower dosage of local anesthetic, the PCEA protocol for Group II was adequate for pain management during labor, particularly in the second stage. This result does not support prior findings despite the use of different techniques, ${ }^{18}$ suggesting that satisfaction with analgesia requires increasing concentrations of local anesthetic as uterine contractility increases. However, this result is in agreement with some aspects of the studies by Bremerich et $\mathrm{al}^{8}$ and Srivastava et $\mathrm{al}^{24}$ who found that basal perfusion was associated with lower incidences of distressing pain and rescue doses during the second stage.

We admit however, as an important contribution to the efficacy of PCEA with $0.06 \%$ ropivacaine (comparable VAS ratings and number of rescue doses in the two PCEA protocols) during labor, specifically in the second stage, the larger number of self-administered boluses, which were infused at an average rate of 1 per $103 \mathrm{sec}$ (standard delivery rate of $175 \mathrm{ml} . \mathrm{h}-1$ ) and at progressively shorter intervals. This action may have promoted the

Table 3 - Side effects

$\begin{array}{ccc}\text { Group I }(n=58) & \text { Group II }(n=57) \\ n & \% & n\end{array}$

$\%$

$p$

\begin{tabular}{|c|c|c|c|c|c|}
\hline \multicolumn{6}{|l|}{ Motor block } \\
\hline Bromage 0 & 44 & 75.9 & 50 & 87.7 & \multirow{3}{*}{0.228} \\
\hline Bromage score 1 & 13 & 22.4 & 6 & 10.5 & \\
\hline Bromage score 2 & 1 & 1.7 & 1 & 1.8 & \\
\hline Pruritus & 10 & 17.2 & 8 & 14.0 & 0.798 \\
\hline Nausea & 5 & 8.6 & 4 & 7.0 & 1.000 \\
\hline
\end{tabular}

Group I: $0.1 \%$ ropivacaine; Group II: $0.06 \%$ ropivacaine.

Table 4 - Models of general equations for repeated measuring of duration of intervals between doses for each one of the groups

\begin{tabular}{|c|c|c|c|c|c|c|}
\hline & \multicolumn{3}{|c|}{ Group I $(\mathrm{n}=58)$} & \multicolumn{3}{|c|}{ Group II (n = 57) } \\
\hline & Beta & $95 \% \mathrm{Cl}$ & $p$ & Beta & $95 \% \mathrm{Cl}$ & $p$ \\
\hline Variation of intervals between doses & 32.61 & $25.39 / 39.82$ & $<0.001$ & -1.40 & $-2.44 /-0.36$ & 0.009 \\
\hline Constant & 39.88 & & & 51.61 & & \\
\hline
\end{tabular}

Group I: $0.1 \%$ ropivacaine; Group II: $0.06 \%$ ropivacaine. 
greater distal progression of the anesthetic solution into the epidural space, thus enabling it to reach the sacral roots more efficiently ${ }^{25}$ as a result of its better distribution in the epidural space due to the pressure that is applied during bolus infusion. ${ }^{26}$ Accordingly, our findings suggest that most important than the concentration of the anesthetic ${ }^{18}$ or the basal perfusion ${ }^{8,24}$ it is possible that larger volumes administered with higher pressure in the epidural space may be necessary for the pelvic blockade during the second stage, and the role of basal perfusion may diminish. ${ }^{1}$ Future research involving ultra-low dose regimens and different settings may reveal new findings in this regard.

There are a number of limitations to this study. The main limitation was the non-randomized design. However, it is worth mentioning that the two groups were comparable with regard to all the characterization variables. It is possible that our findings may be more robust if the background infusion was the same in the two groups; however, as noted above, the similarities of both groups in sufentanil concentrations, opioid administrations, and most notably in equal hourly volume limits, support our findings as mainly dependent upon variations in the ropivacaine dose. The relatively small sample size may have also limited the strength of the conclusions reported herein, considering the statistical tests that were applied and their power to detect small but potentially important differences. In fact, according to Cohen, ${ }^{27}$ post hoc power calculations demonstrated that the achieved sample size only allowed for the detection of medium to large effects. Moreover, the fact that the sample comprised parturients of mixed parity must be considered. It is important to note however that there were no differences between the two groups in this variable. Given the nonrandomized design, the available participants may not have been representative of the pregnant population. We therefore recognize the need for these results to be confirmed and further clarified by prospective and randomized studies with larger sample sizes. Another limitation relates to the difficulty to measure the diagnosis of full cervical dilation and, possibly, the variability in the labor monitoring by the obstetric staff, which may have introduced some bias, and therefore may have affected the recording of the second stage of labor. Nevertheless, the importance of carefully recording the time of full dilatation (and always considering the parturients' comfort) was transmitted and emphasized to the obstetric teams. In this study, the obstetric treatments were conducted according to the local institutional protocol, and all women accordingly received oxytocin for the augmentation of their labor after their epidural blocks were established. Although this is not a universal practice, it is frequent in obstetric care and therefore should be taken into consideration with respect to the generalizability of the findings. Finally, we recognize that maternal satisfaction is a multidimensional factor that has been assessed with a reductive methodology in conventional anesthesiology studies. ${ }^{28}$ However, because a woman's satisfaction with her labor experience may change over time, ${ }^{29}$ we chose to measure this factor soon after delivery, stressing the continuity between maternal satisfaction and the physical and emotional experience of labor.

Despite these limitations, this study also has some methodological strengths. First, although the teams of anesthesiologists were not blinded to the study regimens, they were blinded to all other aspects of the study, and importantly, they were not aware of the results that were obtained by the team that applied the other PCEA protocol. Additionally, it is important to note that the participants and obstetric staff were blinded to the group allocations, thereby contributing to the minimization of the potential bias of this non-randomized study. Second, covariates that may have influenced the results were introduced during the data analysis. Lastly, the PCEA infuser was an important measuring device that recorded and facilitated the transcription of rigorous, important data describing the analgesic characteristics (duration, drug administration, bolus count, and estimate of the interval between boluses).

\section{CONCLUSIONS}

In conclusion, this study suggests that a dose of $0.1 \%$ ropivacaine by PCEA may be related to a cumulative analgesic effect and be associated with a longer second stage of labor. In contrast, a dose of $0.06 \%$ showed less evidence of cumulative effects while maintaining good analgesic efficacy and was associated with a shorter second stage of labor. Considering that the ideal PCEA protocol remains controversial, techniques that limit timedependent cumulative effects, such as the one identified in this study, may enable the reduction of the medicalization of labor and thereby diminish its negative consequences.

\section{CONFLICT OF INTEREST}

The authors have no conflicts of interest to declare.

\section{FUNDING SOURCES}

This study received no external funding.

\section{REFERENCES}

1. Bernard JM, Le Roux D, Vizquel L, Barthe A, Gonnet JM, Aldebert A, et al. Patient-controlled epidural analgesia during labor: the effects of the increase in bolus and lockout interval. Anesth Analg. 2000;90:328-32.

2. Van der Vyver M, Halpern S, Joseph G. Patient-controlled epidural analgesia versus continuous infusion for labour analgesia: a metaanalysis. Br J Anaesth. 2002;89:459-65.

3. De Eccher L, Martino C, Bacchilega I, Rainaldi MP, Baroncini S. Analgesia in travaglio di parto PCEA vs boli. Minerva Anestesiol. 2002;68:83-7.

4. Vallejo MC, Ramesh V, Phelps AL, Sah N. Epidural labor analgesia: continuous infusion versus patient-controlled epidural analgesia with background infusion versus without a background infusion. J Pain. 2007;8:970-5.

5. Lopard E. L'analgésie péridurale obstétricale contrôlée par la patiente : en pratique. Ann Fr Anesth Reanim. 2006;25:593-8.

6. Capogna G, Camorcia M, Stirparo S, Farcomeni A. Programmed intermittent epidural bolus versus continuous epidural infusion for labor analgesia: the effects on maternal motor function and labor outcome. 
A randomized double-blind study in nulliparous women. Anesth Analg 2011;113:826-31

7. Brogly N, Schiraldi R, Vazquez B, Perez J, Guasch E, Gilsanz F. A randomized control trial of patient-controlled epidural analgesia (PCEA) with and without a background infusion using levobupivacaine and fentanyl. Minerva Anestesiol. 2011;77:1149-54.

8. Bremerich $\mathrm{DH}$, Waibel HJ, Mierdl S, Meininger D, Byhahn C, Zwissler $\mathrm{BC}$, et al. Comparison of continuous background infusion plus demand dose and demand-only parturient-controlled epidural analgesia (PCEA) using ropivacaine combined with sufentanil for labor and delivery. Int J Obstet Anesth. 2005;14:114-20.

9. Lim Y, Ocampo CE, Supandji M, Teoh $W H$, Sia AT. A randomized controlled trial of three patient-controlled epidural analgesia regimens for labor. Anesth Analg. 2008;107:1968-72.

10. Okutomi T, Saito M, Mochizuki J, Amano K, Hoka S. A double-blind randomized controlled trial of patient-controlled epidural analgesia with or without a background infusion following initial spinal analgesia for labor pain. Int J Obstet Anesth. 2009;18:28-32.

11. Bernard JM, Le Roux D, Frouin J. Ropivacaine and fentany concentrations in patient-controlled epidural analgesia during labor: a volume-range study. Anesth Analg. 2003;97:1800-7.

12. Ledin Eriksson $\mathrm{S}$, Gentele $\mathrm{C}$, Olofsson $\mathrm{CH}$. PCEA compared to continuous infusion in a ultra-low-dose regimen for labor pain relief: a randomized study. Acta Anaesthesiol Scand. 2003;47:1085-90.

13. Wang F, Shenm X, Guo X, Peng Y, Gu X. Epidural analgesia in the latent phase of labour and the risk of cesarean delivery: a five-year randomized controlled trial. Anesthesiology. 2009;111:871-80.

14. Fitzmaurice GM, Laird NM, Ware JH. Applied longitudinal analysis. Hoboken: Wiley-Interscience; 2004.

15. Pepe MS, Anderson GL. A cautionary note on inference for marginal regression models with longitudinal data and general correlated response data. Commun Stat Simul Comput. 1994;23:939-51.

16. Faul F, Erdfelder E, Lang AG. G*Power3: a flexible statistical power analysis program for the social, behavioral, and biomedical sciences. Behav Res Methods. 2007;39:175-91

17. Carvalho B, Cohen SE, Giarrusso K, Durbin M, Riley ET, Lipman S.
"Ultra-light" patient-controlled epidural analgesia during labor: effects of varying regimens on analgesia and physician workload. Int J Obstet Anesth. 2005;14:223-9.

18. Capogna G, Celleno D, Lyons G, Columb M, Fusco P. Minimum loca analgesic concentration of extradural bupivacaine increases with progression of labour. Br J Anaesth. 1998;80:11-3.

19. Ranasinghe JS, Birnbach DJ. Progress in analgesia for labor: focus on neuraxial blocks. Int J Womens Health. 2010;1:31-43

20. Sultan P, Murphy C, Halpern S, Carvalho B. The effect of low concentrations versus high concentrations of local anesthetics for labour analgesia on obstetric and anesthetic outcomes: a meta-analysis. Can J Anesth. 2013;60:840-54.

21. Melzack R. Labour pain as a model of acute pain. Pain. 1993;53:117-20.

22. Hildingsson I, Karlström A, Nystedt A. Women's experiences of induction of labour-findings from a Swedish regional study. Aust N Z J Obstet Gynaecol. 2011;51:151-7.

23. Boselli E, Debon R, Duflo F, Bryssine B, Allaouchiche B, Chassard D. Ropivacaine $0.15 \%$ plus sufentanil $0.5 \mathrm{microg} / \mathrm{mL}$ and ropivacaine $0.10 \%$ plus sufentanil $0.5 \mathrm{microg} / \mathrm{mL}$ are equivalent for patient-controlled epidural analgesia during labor. Anesth Analg. 2003;96:1173-7.

24. Srivastava U, Gupta A, Saxena S, Kumar A, Singh S, Saraswat N, et al. Patient controlled epidural analgesia during labour: effect of addition of background infusion on quality of analgesia \& maternal satisfaction. Indian J Anaesth. 2009;53:649-53.

25. Power I, Thoranburn J. Differential flow from multiholed epidura catheters. Anaesthesia. 1988;43:876-8.

26. Wong CA, Ratliff JT, Sullivan JT, Scavone BM, Toledo P, Robert J, et al. A randomized comparison of programmed intermittent epidural bolus with continuous epidural infusion for labor analgesia. Anesth Analg. 2006;102:904-9.

27. Cohen J. A power primer. Psychol Bull. 1992;112:155-9

28. Ross A. Maternal satisfaction with labour analgesia. Baillieres Clin Obstet Gynaecol. 1998;12:499-512.

29. Hodnett ED. Pain and women's satisfaction with the experience of childbirth: a systematic review. Am J Obstet Gynecol. 2002;186:S16072. 


\section{Effects of Local Anesthetic on the Time Between Analgesic Boluses and the Duration of Labor in Patient-Controlled Epidural Analgesia: Prospective Study of Two Ultra-Low Dose Regimens of Ropivacaine and Sufentanil}

Acta Med Port 2015:28:70-76

Publicado pela Acta Médica Portuguesa, a Revista Científica da Ordem dos Médicos

Av. Almirante Gago Coutinho, 151

1749-084 Lisboa, Portugal.

Tel: +351218428 215

E-mail: submissao@actamedicaportuguesa.com

www.actamedicaportuguesa.com

ISSN:0870-399X | e-ISSN: 1646-0758

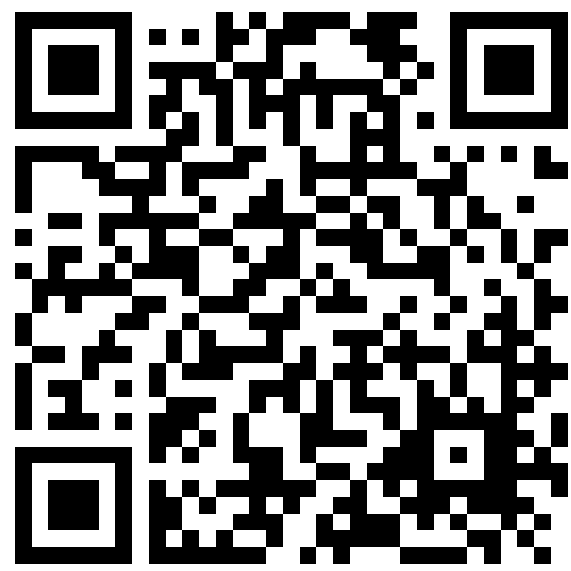

